\title{
EDITORIAL
}

\section{PENSAR “HERETICAMENTE” A MOBILIDADE HUMANA NA CONTEMPORANEIDADE}

\author{
Think "heretically" human mobility in contemporary times
}

Roberto Marinucci*

A capacidade de pensar criticamente, de compreender a complexidade "das relações e das inter-retroações entre cada fenômeno e seu contexto" (Morin, 2006, p. 25), bem como a capacidade de transcender os localismos e as "tocas culturais" (Augé, 2010b, p. 91) são elementos essenciais para a saúde de qualquer democracia. O pensamento crítico, ou herético, questiona argumentativamente os dogmas hegemônicos difundidos nas sociedades, introduzindo "dissonâncias cognitivas" (Berger, Zilderveld, 2011, p. 34) que erodem o pensamento único e desnaturalizam crenças essencializadas.

Os estudos sobre a mobilidade migratória não fogem desses desafios. Epistemologias construídas e sustentadas a partir de interesses específicos e particulares - o "pensamento de Estado", o "nacionalismo metodológico", o "eurocentrismo colonial" - acabam por impor e difundir como sendo evidentes, objetivos e neutrais, enfoques teóricos, perspectivas analíticas, nomenclaturas e taxonomias que condicionam, senão determinam, o olhar sobre o fenômeno. Desta maneira, na conjuntura contemporânea, o amplo e complexo universo da mobilidade e imobilidade humanas acaba sendo, frequentemente, enquadrado em abordagens analíticas que, não raramente, criminalizam tanto seus protagonistas quanto os que com eles se solidarizam (Penchaszadeh, Sferco, 2019).

Surge, diante disso, a necessidade da construção de epistemologias heréticas, alternativas, com vistas a desmascarar os conflitos e os interesses de poder envolvidos nas disputas sobre mobilidade humana; fortalecer a "mobilidade do espírito" (Augé, 2010b, p. 90) em relação ao espaço

Editor-chefe da Revista REMHU, Centro Scalabriniano de Estudos Migratórios (CSEM). Brasília DF, Brasil. E-mail: remhu@csem.org.br. Orcid: 0000-0002-2042-2628. 
(capacidade de sair da própria toca geo-cultural) e ao tempo (capacidade de olhar para a contemporaneidade, em diálogo constante com o passado e em vista à construção do futuro); considerar a complexidade das estruturas, que abrangem conexões dialéticas e multi-escalares entre fatores econômicos, políticos, culturais e demográficos; ressaltar a agency de migrantes e refugiados, não apenas em termos individuais, mas também coletivos.

Vale a pena atentar para este último aspecto: pensar os sujeitos da mobilidade como agentes ativos que, embora condicionados por inevitáveis contingências biográficas e estruturais, desenvolvem de forma resiliente táticas de enfrentamento da realidade adversa (Certeau, 2008), não apenas individualmente, mas também mediante mobilizações e organizações coletivas. Conhecer a realidade migratória a partir de seus atores, dar-lhes voz, imaginar-se empaticamente no lugar deles (Nussbaum, 2014), vê-los antes como sujeitos políticos de direitos que como vidas vitimadas e sofridas (Fassin, 2019) são elementos que podem gerar uma "contaminação cognitiva" (Berger, Zijderveld, 2011, p. 34), possibilitar o surgimento de enfoques teóricos e perspectivas analíticas alternativos que, sem dúvidas, podem auxiliar nos processos políticos de transformação da realidade social na ótica dos direitos dos indivíduos e dos povos.

Sobre essa temática verte o Dossiê da REMHU, Revista interdisciplinar da Mobilidade Humana, n. 57. Alguns dos artigos propõem novas chaves analíticas de leitura; outros reinterpretam enfoques clássicos; outros, ainda, se limitam a reafirmar e a pautar "obviedades" às vezes propositalmente encobertas ou esquecidas. Em todo caso, são apresentadas pistas para repensar "hereticamente" enfoques teóricos e perspectivas analíticas, focando uma contemporaneidade "historicizada", interpretada como produto de processos históricos e voltada para a construção do futuro (Augé, 2010a, p. 88).

Noel Salazar, no primeiro artigo do Dossiê, analisa os desafios teóricos e metodológicos dos estudos contemporâneos sobre os movimentos migratórios, enfatizando, especificamente, a "mobilidade" enquanto categoria analítica. O autor apresenta criticamente algumas das principais contribuições teóricas sobre a temática, evidenciando avanços, limites e desafios. Paradoxalmente, segundo Salazar, a questão migratória, que pressupõe mobilidade, é com frequência abordada de forma estática - antes e depois do deslocamento -, focalizando sujeitos marcados pela "imobilidade" (física ou simbólica): confinados, por exemplo, em campos de refugiados, prisões ou áreas de fronteiras. Faz-se necessário, nesta perspectiva, que os estudos sobre mobilidade migratória considerem também os regimes, as estruturas e os dispositivos que, de fato, impedem ou dificultam a livre circulação das pessoas. 
Gennaro Avallone desenvolve uma crítica metodológica e epistemológica das formas predominantes de interpretar as migrações contemporâneas, visando "desnaturalizar las visiones hegemónicas basadas en el pensamiento de Estado y la colonialidad" que contribuem "a reproducir, al nivel de la organización del pensamiento y del lenguaje, la subordinación de las personas migrantes en las sociedades de inmigración, especialmente cuando ellas son herederas de la subalternidad colonial". Citando Sayad, o autor questiona aquelas categorias administrativas "Estado-étnico-céntricas" que, de fato, condicionam profundamente a representação e a intelecção da mobilidade humana, tendo uma forte influência, inclusive, nas ciências sociais.

Lourdes Basualdo, Eduardo Domenech e Evangelina Pérez, por sua vez, analisam criticamente as cartografias hegemômicas das migrações e das fronteiras, propondo, em contraposição, novas formas de mapeamento do território, um "contramapeo" coletivo, "desde abajo" e sensível às lutas e às mobilizações de migrantes, refugiados e outros grupos vulnerabilizados. Os autores visam recuperar "Ios conflictos, las divisiones y las disputas de poder que las fronteras contienen, desde la perspectiva de quienes protagonizan los movimientos y los cruces". Em outros termos, uma "cartografía herética" desafia e questiona a positividade e a neutralidade das representações cartográficas hegemônicas e, de forma mais ampla, da produção de conhecimento sobre a mobilidade humana.

O questionamento das "metáforas hidráulicas" utilizadas nos estudos migratórios é o ponto de partida da reflexão de Gustavo Dias, que busca complexificar a compreensão dos deslocamentos humanos a partir de categorias como "mobilidade migratória", "fronteiras inteligentes" e "espaço social". "Fluxos", "ondas", "tsunamis" e outros termos análogos tendem, por um lado, a destacar os aspectos "ameaçadores" das migrações e, por outro, a enfatizar seu determinismo em termos de rotas. O autor atenta para a mobilidade como "prática social", realçando o protagonismo das pessoas migrantes e suas táticas de mobilidade migratória, sobretudo nos espaços de fronteira - físicas e simbólicas. As táticas, sustenta o autor, trazem "a ideia de autonomia, capacidade de negociação e superação por parte de migrantes, que passam a ser compreendidos enquanto atores" que interferem nos processos de mobilidade migratória.

As interações e as tensões entre estrutura e agency são focadas no artigo de Marta Carballo de la Riva, Enara Echart Muñoz e María del Carmen Villarreal Villamar, que desenvolvem uma revisão da literatura sobre o enfoque de sistemas migratórios, com o objetivo de apresentar uma ferramenta teórica para analisar a conjuntura migratória da América Latina e Caribe. Entre outros aspectos, as autoras destacam a necessidade de levar em conta a estrutura (economia, meio ambiente), os fatores intermediários (instituições, políticas migratórias, 
redes) e a agência dos migrantes, sendo esta interpretada não apenas numa ótica individual, mas também coletiva - a partir dos movimentos populares de protesto e reivindicação, como as caravanas na América Central. As pessoas migrantes - inferem as autoras - deixam "de ser solamente una consecuencia de los desequilibrios estructurales para convertirse en sujetos políticos capaces de organizarse y articular demandas concretas que cuestionan las estrategias tradicionales de control, gestión e interpretación del fenómeno migratorio, así como nociones clásicas sobre Estados, fronteras o ciudadanía".

Alejandro Canales propõe uma análise da questão migratória enquanto elemento central para a sustentabilidade dos processos de "reprodução" demográfica, social e econômica das sociedades avançadas no contexto contemporâneo. Os deslocamentos humanos, de fato, permitem compensar os déficits de população e de força de trabalho, além de sustentarem um mercado de trabalho rigidamente estratificado e racializado. Isso, no entanto, gera um "mal-estar" entre as populações autóctones, pois, apesar de necessárias, essas compensações demográficas acabam alterando étnica e culturalmente o perfil dos países. Ou seja, a reprodução social e econômica "requiere de amplios contingentes de fuerza de trabajo para su explotación y extracción de valor (trabajo) y su capitalización. Pero por otro lado, esta fuerza de trabajo no existe en abstracto, sino que bajo la forma de personas, de inmigrantes de carne y hueso, con derechos sociales, humanos, económicos y laborales". O que fazer com esses migrantes que teimam em ser reconhecidos como "seres humanos"?

A questão demográfica é focada especificamente por Marden Barbosa de Campos, que apresenta um arcabouço conceitual para aprimorar a compreensão das dinâmicas migratórias contemporâneas a partir de uma abordagem multiescalar que relaciona as migrações às transições por que passam indivíduos, famílias e populações. Essa proposta teórica busca superar a fragmentação disciplinar nos estudos migratórios e integrar processos que ocorrem em diversos níveis escalares - a saber, "a seletividade etária da migração, as alterações na configuração domiciliar e as mudanças no padrão migratório da população". Em outros termos, as migrações devem ser inseridas e analisadas num contexto demográfico dinâmico e em constante transformação, que altera a propensão migratória das pessoas envolvidas.

João Peixoto se debruça sobre a migração contemporânea a partir das categorias de hipermobilidade ou supermobilidade. Revisitando as principais teorias migratórias e apresentando as tendências atuais tanto da mobilidade internacional quanto da conjuntura econômica, política e demográfica, o autor procura "entrever o que pode suceder no futuro face às mudanças globais", em termos de continuidade e aprofundamento dos rumos atuais das dinâmicas migratórias, ou, pelo contrário, em termo de retração ou contenção. $\mathrm{Na}$ opinião do autor, a constante tensão entre fatores estruturais e agência 
individual dificulta a tarefa de desenhar cenários previsíveis das dinâmicas migratórias vindouras, ainda que haja sinais de continuidade ou fortalecimento dos movimentos migratórios mundiais.

A compreensão da mobilidade migratória tem também implicações éticas. Juan Carlos Velasco oferece pistas para repensar o entendimento das noções de "fronteira" e "muro", frequentemente utilizadas como sinônimos, mas que, na realidade, possuem significados distintos: a primeira, diferentemente do muro, visa regulamentar os trânsitos, os intercâmbios, não sendo, portanto, um dispositivo obstrutivo. A noção de "fronteiras abertas" (open borders) é proposta pelo autor para superar a visão um pouco quimérica de um mundo "sem fronteira" (borderless world) e, por outro lado, para estabelecer um regime migratório solidário que respeite os valores básicos das sociedades democráticas. Para isso, é fundamental também desnaturalizar a retórica hegemônica da necessidade de muros e barreiras, evidenciando seu caráter substancialmente ineficaz, oneroso e violento.

Na seção Artigos, Renato Zerbini apresenta as principais características do regime de proteção aos migrantes, refugiados e solicitantes de refúgio que emerge do Pacto Internacional de Direitos Econômicos, Sociais e Culturais das Nações Unidas. Em um contexto internacional marcado pelos crescentes ataques às lógicas e às práticas do multilateralismo, uma análise sobre esse regime se torna relevante e até necessária.

O teólogo e cientista da religião Jung Mo Sung, interpelado pelo aumento da criminalização de pessoas migrantes e, inclusive, daqueles que se solidarizam com elas, reflete sobre o fenômeno migratório contemporâneo a partir das categorias de "idolatria" e "sacrifício". O autor busca identificar elementos que permitam compreender a racionalidade que legitima a inferiorização e "desumanização" dos "migantes-inimigos" e dos "solidários-traidores".

Por fim, Edmar Aparecido de Barra e Lopes se debruça sobre o processo de reconstrução de laços entre passado, presente e futuro por parte de migrantes internos em uma ocupação no Estado de Goiás, no centro-oeste do Brasil. As narrativas analisadas revelam a intersecção diacrônica e sincrônica dos tempos da festa e do trabalho, da família e da religião, numa busca resiliente de respostas aos desafios da integração e da reinterpretação das jornadas.

Na seção Relatos e Reflexões, Avelino Chico reflete sobre a ação da Conferência Episcopal de Angola, no que diz respeito a migrantes, refugiados e solicitantes de refúgio. O autor destaca a evolução histórica, detalha as principais características da ação sociopastoral e conclui propondo algumas ações frente aos desafios da conjuntura atual. 
A resenha de Roberto Marinucci, sobre o livro Conversioni: verso un nuovo modo di credere? Europa, pluralismo, Islam de Stefano Allievi encerra o número da revista.

Desejamos a todas e todos uma boa leitura.

\section{Referências bibliográficas}

AUGÉ, Marc. Che fine ha fatto il futuro? Milano: Elèuthera, 2010a.

AUGÉ, Marc. Per una antropologia della mobilità. Milano: Jaka Book, $2010 \mathrm{~b}$.

BERGER, Peter; ZIJDERVELD, Anton. Elogio del dubbio. Milano: II Mulino, 2011.

CERTEAU, Michel de. A invenção do cotidiano: 1. Artes de fazer. Petrópolis: Vozes, 1998.

FASSIN, Didier. Vite ineguali. Quanto vale un essere umano. Milano: Feltrinelli, 2019.

MORIN, Edgar. A cabeça bem-feita. Rio de Janeiro: Bertrand Brasil, 2003.

NUSSBAUM, Martha. Non per profitto. Perché le democrazie hanno bisogno degli studi umanistici. Milano: II Mulino, 2014.

PENCHASZADEH, Ana Paula; SFERCO, Senda Inés. Solidaridad y Fraternidad. Una nueva clave ético-política para las migraciones. REMHU, Revista Interdisciplinar da Mobilidade Humana, Brasília, v. 27, n. 55, p. 149-164, 2019. 